\title{
Allogeneic mesenchymal stem cell transplantation in healthy equine superficial digital flexor tendon: A study of the local inflammatory response
}

\author{
Jaqueline Souza Brandão ${ }^{\mathrm{a}}$, Marina Landim Alvarenga ${ }^{\mathrm{a}}$, João Pedro Hubbe Pfeifer ${ }^{\mathrm{a}}$, \\ Vitor Hugo dos Santos ${ }^{\mathrm{a}}$, Carlos Eduardo Fonseca-Alves ${ }^{\mathrm{b}}$, Mirian Rodrigues $\mathrm{s}^{\mathrm{a}}$, \\ Renée Laufer-Amorim ${ }^{b}$, José Antonio Lucas Castillo ${ }^{a}$, Ana Liz Garcia Alves ${ }^{a, *}$ \\ a Department of Veterinary Surgery and Anesthesiology, School of Veterinary Medicine and Animal Science, São Paulo State University (UNESP), Distrito de Rubião Júnior \\ $s / n$, Botucatu, SP 18618-9070, Brazil \\ ${ }^{\mathbf{b}}$ Department de Veterinary Clinic, School of Veterinary Medicine and Animal Science, São Paulo State University (UNESP), Distrito de Rubião Júnior s/n, Botucatu, SP \\ 18618-9070, Brazil
}

\section{A R T I C L E I N F O}

\section{Keywords:}

Allogeneic

Immunologic response

Mesenchymal stem cells

Inflammation

Equine

\begin{abstract}
A B S T R A C T
The superficial digital flexor tendon (SDFT) is a structure frequently affected by injuries in high-performance athletic horses, and there are limited therapeutic options. Regenerative medicine has evolved significantly in treating different illnesses. However, understanding the cellular behaviour during mesenchymal stem cell (MSC) transplantation in healthy tissues is not fully known yet. To address the inflammatory response induced by allogeneic MSC transplantation, this study evaluated the local inflammatory response after the application of allogeneic adipose tissue-derived mesenchymal stem cells (AT-MSCs) in the equine tendon compared to an autologous transplant and the control group. Eighteen thoracic limbs (TL) in nine animals were divided into three groups and subjected to the application of AT-MSCs in the healthy tendon. In the allogeneic group (Gallog), the animals received an allogeneic AT-MSC application in the TL. The autologous group (Gauto) received an application of autologous cells in the TL, and in the control group (Gcont), phosphate-buffered saline (PBS) was applied. There were no significant differences among the evaluated groups in the physical, morphological, thermography, and ultrasonography analyses. A higher number of CD3-positive lymphocytes was observed in the Gauto group compared to the control $(\mathrm{P}<0.05)$. Additionally, we did not observe different expressions of CD172 and microvascular density among the groups. The allogeneic transplantation of AT-MSCs did not result in an adverse or inflammatory reaction that compromised the use of these cells in this experiment. Their behaviour was similar to that of autologous transplantation.
\end{abstract}

\section{Introduction}

Mesenchymal stem cells (MSCs) are easily isolated and expanded in vitro, which makes them promising targets for application in clinical trials, particularly for regenerative medicine, cell therapy and tissue engineering (Alberts et al., 2004). Mesenchymal cells are multipotent adult cells with immunomodulatory and regenerative properties and, given their therapeutic potential, have been extensively studied to evaluate their safety and efficiency (Guadix et al., 2017).

The literature exposes several positive competences inherent in MSCs. It is known that these cells have a capacity for expansion and differentiation, have a chemotactic effect, and are capable of performing local immunomodulation (Yamada et al., 2013; De Wolf et al., 2017; Mohammadi Ayenehdeh et al., 2017). More recently, it has become increasingly clear that cells exert a favourable effect by secreting cytokines and other paracrine factors, growth factors, antifibrotic factors, and angiogenic mediators, which involves and recruits receptor cells during tissue repair (Da Silva Meirelles et al., 2009; Tolar et al., 2010; Caprnda et al., 2017). According to Smith and Mcllwraith (2014), the current challenges in MSC transplantation includes modulating the beneficial and harmful effects of the inflammation and the local cellular response secondary to the application of stem cells.

Enthusiastic authors claim that the use of allogeneic MSCs may be an alternative therapy for tendinopathies and osteoarthritis, since these cells do not promote an allergic reaction or rejection. In addition, MSC therapy is not associated with tumour development (Díez-Tejedor et al., 2014). A previous study by our research group associates adipose tissue-derived mesenchymal stem cells (AT-MSCs) with platelet-rich

\footnotetext{
* Corresponding author.

E-mail address: anaalves@fmvz.unesp.br (A.L.G. Alves).
} 
plasma for experimentally induced tendinitis therapy. The treated subjects had the lowest number of inflammatory cells and a shorter recover time compared to the control group (Carvalho et al., 2013). This result was due to the immunomodulatory action presented by the therapeutic association. In studies with patients with autoimmune diseases, Anderson and Bluestone (2005), Seo et al. (2006) and Frassoni et al. (2008) reported that MSCs promote local immunosuppression and stimulate the mechanisms of regeneration through paracrine effects involving the production of anti-inflammatory and immunoregulatory molecules and angiogenic growth factors. All these results indicate that MSC treatment is a promising therapeutic choice for patients with locomotor injuries.

The cellular mechanism of innate immunity involved in MSC allogeneic and autologous transplantation is under discussion (Yamada et al., 2013; Yan et al., 2014). Yan et al. (2014) demonstrated that MSCs contribute to the immunomodulatory capacity of regulatory $\mathrm{T}$ cells (Treg) by increasing their suppressor potential. As observed by Tang et al. (2017), T lymphocytes play an important role in cell-mediated immunity. CD3 is an important cell surface marker of T lymphocytes and is essential for the activation of these cells. The CD172a molecule, also known as alpha signal regulatory protein (SIRP $\alpha$ ), is a cell membrane glycoprotein expressed in monocytes, granulocytes, dendritic cells, and CD34 + CD38 - haematopoietic progenitor cells but not in T and B lymphocytes. Studies show that CD172a is involved in dendritic cell-mediated $\mathrm{T}$ cell activation, neutrophil migration and phagocytosis. Thus, the presence of T-lymphocytes associated with high levels of CD172 promotes an activation of the local immune response. On the other hand, this inflammatory process induces angiogenesis for the resolution of the inflammatory process (Imhof and Aurrand-Lions, 2006).

The use of allogeneic MSCs in equine tendinitis is justified by the fact that cultured cells obtained from equine donors (allogeneic treatment) can be used, offering the advantage of a faster treatment by using a homogeneous cell population with a proven differentiation capacity (Borjesson and Peroni, 2011). In addition, MSCs can be phenotyped and karyotyped prior to administration, so that the cells with an immunomodulatory ability and a desirable proliferative capacity can be selected for therapeutic applications (Carrade et al., 2011b). Thus, immunoreactivity tests of allogeneic MSCs are extremely relevant to ensure safe therapy, and many studies still need to be performed so that the real behaviour of stem cells at the application site can be understood. The development of an allogeneic tissue bank of MSCs for therapeutic applications allows for the use of cell therapy in acute lesions rather than being limited to waiting for the time inherent to the culture of the autologous cells (Carrade et al., 2011b).

Most of the studies on MSC behaviour are conducted in models of tissue injury, but the evaluation of these cells when applied in healthy tissue is necessary to better understand their behaviour and mechanism of action in cell therapy. Applying allogeneic MSCs in an intact host tissue allows for the evaluation of the local inflammatory reaction after the transplantation of these cells without any interaction of other factors, which demonstrates that the possible alterations are actually generated by the cellular transplantation (Gala et al., 2013).

The study of MSC behaviour in healthy tissue is essential for establishing the safety and predicting the side effects of allogeneic mesenchymal stem cell transplantation in equines. The study of MSC behaviour is the first step to better understanding cell therapy. However, there is limited information regarding the allogeneic transplantation of MSCs in equine patients. For a better understanding of the cellular response against MSCs transplantation in equines, this research aimed to evaluate the inflammatory response resulting from the transplantation of AT-MSCs in healthy tendon tissue in order to qualify and quantify the local inflammatory response by physical, ultrasonographic, histopathological, and inflammatory immunomodulatory parameters.

\section{Materials and methods}

\subsection{Experimental design}

This study was approved by the Ethics Committee on Animal Use under the protocol number: 18/2014-CEUA. Nine healthy 4-to-8-yearold castrated male and female horses weighing, on average, $337 \mathrm{~kg}$, with no history of locomotor affections, were selected. The 18 superficial digital flexor tendons (SDFT) of the thoracic limbs (TL) were utilized for the application of MSCs and were divided into 3 distinct groups with 6 tendons each, and the animals were randomly distributed and the test was set up under blinded conditions. The Gallog group refers to the animals that received the application of allogeneic ATMSCs in the middle third of the thoracic limb. The Gauto group are animals that received the application of autologous cells in the middle third of the TL, and the Gcont group, which received phosphate buffered saline (PBS) (Sigma-Aldrich, St. Louis, MO, USA), was the control group.

\subsection{Adipose tissue extraction and AT-MSC isolation and culture}

The AT-MSCs were obtained and cultured from the adipose tissue of these same experimental horses. The extraction of the stromal vascular fraction and the cell culture were performed according to the technique for horses described by Yamada et al. (2013) and Carvalho et al. (2013). After the analysis, the data were evaluated by software from the same manufacturer (BD FACSDiva ${ }^{\mathrm{TM}}$ software v6.1). The characterization of the MSCs was performed by flow cytometry (LSR Fortessa - Becton Dickinson, Mountain View, CA, USA, equipped with 3 lasers: 488-nm blue, $100 \mathrm{~mW}$; $640-\mathrm{nm}$ red, $40 \mathrm{~mW}$; and $405-\mathrm{nm}$ violet, $100 \mathrm{~mW}$ ) prior to their application according to Yamada et al. (2013) and Carvalho et al. (2009). For further characterization, part of the MSCs obtained for the application were subjected to differentiation using commercial kits for cartilage tissue (STEMPRO Chondrogenesis Differentiation Kit GIBCO - Invitrogen Cell Culture, USA), bone tissue (STEMPRO Osteogenesis Differentiation Kit GIBCO - Invitrogen Cell Culture, USA) and adipose tissue (STEMPRO Adipogenesis Differentiation Kit GIBCO Invitrogen Cell Culture, USA) according to the manufacturer's instructions.

The initial phase of the experiment was the week in which the adipose tissue was collected followed by the isolation and culture of the AT-MSCs. The cells were cryopreserved at passage three to simulate cell bank conditions. These cells were frozen in cryotubes at the concentration of $1 \times 10^{6}$ cells per $\mathrm{mL}$ of Bambanker ${ }^{\circledast}$ commercial cryopreservation medium (Lymphotec Inc., Tokyo, Japan) at $-80^{\circ} \mathrm{C}$. The cells were evaluated by flow cytometry, post-thawing, to observe the viability with at least $91 \%$ mean intact cells, to ensure cell banking worked well. The previously cryopreserved cell samples were thawed in a water bath at $37^{\circ} \mathrm{C}$ for $2 \mathrm{~min}$ one week prior to their application, and $1 \times 10^{7}$ cells were prepared for each application and was resuspended in PBS before transplantation. The number of cells applied was 10 million per tendon.

The PBS medium was used for cell transplantation at passage four because in this phase there is a more homogeneous cell culture. The ATMSCs were evaluated for microbiological and mycological tests, and the cell culture were negative for both.

\subsection{AT-MSC transplantation}

The transplantation of the cells was performed in the middle region of the metacarpus, which was measured with a tape measure from the carpus and ultrasonically guided to determine the appropriate location and depth. It was performed at a single point in the SDFT using a $30 \times 08 \mathrm{~mm}$ needle, and the application was in a total volume of $1 \mathrm{~mL}$. 


\subsection{Evaluations - physical examination}

The animals were evaluated daily by a physical examination taking into account the local volume increase, the presence or absence of heat, pain sensitivity to the palpation of the thoracic limbs and a measurement of the limb perimetry at the application site by using a tape measure. The horses were evaluated every $48 \mathrm{~h}$ by ultrasound, thermographic and lameness examinations. One week (d7) after the implantation of the AT-MSCs, an SDFT biopsy of the thoracic limbs of all the experimental animals was performed.

\subsection{Ultrasonographic examination}

The ultrasonographic examination was performed with an $18 \mathrm{MHz}$ linear transducer (MyLab 70 XVision ESAOTE, VariableBand Linear Array transducer, $18 \mathrm{MHz}$ ) with the animal in equine restraint equipment and with the TL subjected to trichotomy. The evaluation was performed in a transversal and longitudinal plane, and the criteria observed were echogenicity, parallelism among the tendinous fibres, the presence of neovascularization (Power Doppler), and the tendon area. The normality parameter was observed before the application, and it was characterized by the presence of hypoechoic fibres separated by fine hyperechogenic parallel septa, with the SDFT being more hypoechoic than the deep digital flexor tendon (DDFT) (Whitcomb, 2004). The evaluation moments were before, during, and every $48 \mathrm{~h}$ after the cell application.

The Doppler analysis was performed according to Murata et al. (2012). Briefly, the ultrasonographic analysis was classified as absent colour activities (grade 0), grade 1 when a small and rhythmically colour activity was observed, grade 2 when pulsatile and unequivocal colour activity was observed and grade 3 when the colour activity appeared as blood in a regular direction.

\subsection{Thermographic examination}

The thermographic examination was performed with a FLIR SC660 Systems camera directed to the middle region of the metacarpal in the assessed limb, followed by image capture in the plantar-dorsal direction at the TL. The real-time imaging was performed with the animal in the quadrupedal position and still. Then a rectangle was designed to cover both the application site and the area adjacent to it, and the minimum and maximum temperature were recorded, and the local average was calculated. This procedure was performed in all the animals in each group at the evaluation moments (d0, d2, d4, and d6) (Basile et al., 2010).

\subsection{Lameness exam}

The assessment of limb lameness was performed with the animal at a trot and was graded in scores of 0 to 5 according to Stashak (2006).

\subsection{SDFT biopsy}

After one week of the cell transplantation, all the groups were subjected to biopsies (d7). The biopsy was performed in the TL of all the horses aiming for a macroscopic and microscopic analysis of the eventual inflammatory reaction after the transplantation of the allogeneic cells (Gallog) compared to the group that received the autologous cells (Gauto) and to the Gcont group, which received PBS. Once the application region was located, a $1 \mathrm{~cm}^{2}$ fragment of the tendon was excised. The samples collected from the TL were fixed in $10 \%$ neutral buffered formalin and paraffin-embedded for the histopathological and immunohistochemical evaluations.

All the tissue sections were processed and analysed in the Department of Pathology of the School of Veterinary Medicine and Animal Science of São Paulo State University (UNESP), Botucatu
Campus. In the histopathological analysis, the presence of an inflammatory reaction was verified through the degree of tissue organization and the presence and qualifying of the inflammatory infiltrate according to cell type, following the parameters described by Nixon et al. (2008). The intensity of the inflammatory infiltrate was evaluated according to Dias et al. (2016). Briefly, the assessment can be summarized as follows: a score of 0 or absent: the absence of inflammatory infiltrate; a score of 1 or barely discernible: 1 to 10 mononuclear inflammatory cells in a high power field (400x), showing a focal distribution; a score of 2 or mild: 11 to 20 mononuclear inflammatory infiltrates in a high power field $(400 \times)$, with a multifocal distribution; and a score of 3 or intense: $>20$ mononuclear inflammatory cells in a high power field (400x), with a diffuse distribution.

\subsection{Immunohistochemical analysis}

For the immunohistochemical evaluation, four micrometre thick sections were obtained from the paraffin blocks and were distended on histological glass slides with a positive charge (Immunoslide, EasyPath, São Paulo, Brazil). Primary antibodies against the CD172a (Biolegend, Cambridge, UK), CD3 (Dako, Carpinteria, CA, USA) and factor VIII (Dako, Carpinteria, CA, USA) were used. As a secondary antibody, the polymer system (Envision, Dako, USA) was used and was incubated in an oven at $27^{\circ} \mathrm{C}$ for one hour for the antibodies CD3 and CD172a and for $30 \mathrm{~min}$ for factor VIII. The CD3 and CD172a antibodies had crossreactivity with the equine tissue provided by the manufacturer, and the Factor VII antibody was previously validated (Carvalho et al., 2013). The slides were observed under a Confocal Zeiss microscope LSM 510 microscope.

To determine the expression of the markers in the tendons of the animals, the whole section was evaluated; afterwards, five fields of each fragment with the greatest expression were selected. For CD172a and microvascular density (MVD - anti-factor VIII) evaluation, the percentage of stained cells was determined using the ImageJ program by establishing a "threshold" according to Da Silva et al. (2017), which determined the percentage of stained cells. In addition, a grid reticle count of the field-stained lymphocytes was carried out for the CD3 antibody (a total of 5 fields per sample). All the images were captured by the cameras attached to the microscopes and their software.

\subsection{Statistical analysis}

For the statistical analyses of the vascularity evaluation (Power Doppler), the echogenicity of the SDFT on the ultrasound examination, the limb lameness, and the pain sensitivity to palpation and heat, the Friedman non-parametric test (Repeated Measures) was used to compare the evaluation days of each group separately, and for the comparison of the groups on each day, the Kruskal-Wallis test was performed. For the ultrasound parameters of the tendon, perimetry, and thermography, a Repeated-Measures Analysis of Variance was performed to compare the evaluation days of each group separately and to compare the groups on each day, an Analysis of Variance (ANOVA) was performed. When the thermography was significant, a Tukey's test was used to compare the averages. A Chi square or Fisher's exact test was used for a proportion of the animals for the inflammatory infiltrate, fibroblasts, and the linearity of the collagen fibres. Statistical differences among the groups, with regard to CD3, CD172 and the microvascular density expression, were evaluated by an ANOVA, and the significant differences between two categorical variables were evaluated by a Kruskal-Wallis test. The level of significance considered was $\mathrm{P}<0.05$ for all the analyses. 


\section{Results}

\subsection{Physical evaluation}

In the physical evaluation of the animals, the TL perimeters were modified as a whole, as a function of time, especially for the allogeneic group, which presented a greater variation of perimetry (Supplementary Table 1). There was no significant difference between the groups regarding pain sensitivity to palpation. All of the groups (Gallog, Gauto and Gcont) showed a mild pain sensitivity on the second day after the application of the MSCs, which disappeared on the following days. Regarding the presence of heat, there was no significant difference between the groups; although, the Gallog group presented a discrete heat oscillation at the application site compared to Gauto and Gcont groups.

Tendon areas increased as a function of time for the three groups. The groups presented differing behaviours as a function of time, and a greater variation of the tendon area was observed in the Gallog group.

\subsection{Lameness exam and thermography}

The analysis of the lameness exam showed no significant difference between the groups. The animals presented degree 1 lameness after the cell application on $\mathrm{d} 2, \mathrm{~d} 4$ and $\mathrm{d} 6$, while the thermographic analysis showed that the temperature varied in the groups as a function of time (Table 1 and Fig. 1).

\subsection{Ultrasonographic examination}

No significant difference was observed in the ultrasonographic examination after the mesenchymal stem cell transplantation among the groups. Additionally, there was no significant difference between Gauto versus control or Gallog versus control and Gauto versus Gallog (Table 2 and Fig. 2).

At the Power Doppler, the grades 1, 2 and 3 changed little as a function of time for the neovascularization evaluation, and the groups differed as a function of time, showing the presence of blood flow in common to Gauto and Gallog on d4 ( $96 \mathrm{~h}$ post-application). There was no significant difference for the blood flow among the Gauto, Gallog and control groups.

\subsection{Histopathological examination}

The histopathological examination revealed the presence of inflammatory infiltrate in all the groups. All the groups presented only mononuclear inflammatory infiltrate, and only a discrete tissue disorganization was observed. Regarding the inflammatory infiltrate, four samples from the Gcont group had a mild inflammatory infiltrate (score 2 ), and the other two presented a moderate inflammatory infiltrate (score 3). Three samples from the Gauto group presented a mild inflammatory infiltrate (score 2), and the other three presented a moderate inflammatory infiltrate (score 3 ). Three samples (1/6) from the Gallog group had no inflammatory infiltrate, three samples $(3 / 6)$ had a mild inflammatory infiltrate (score 2) and the other two had a moderate

\section{Thermography}

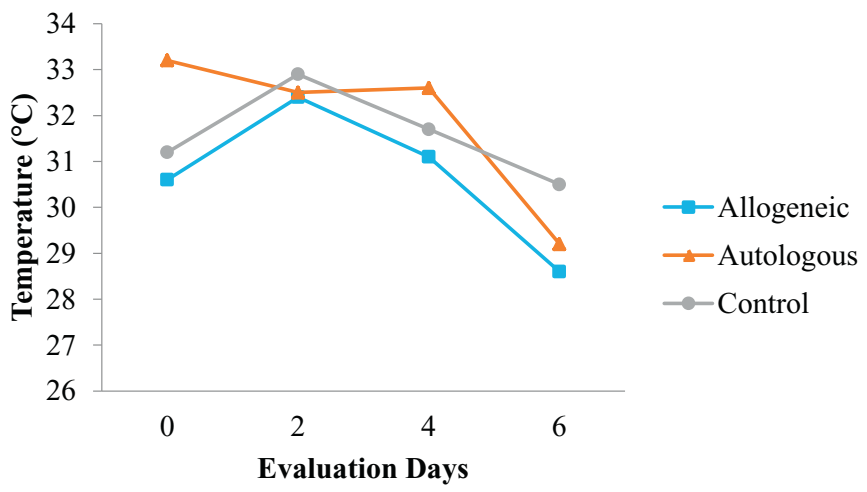

Fig. 1. Temperature variation $\left({ }^{\circ} \mathrm{C}\right)$ evaluated by a thermograph in the different experimental groups, including the Gallog, Gauto and Gcont groups.

Table 2

Mean and standard deviation of the Ultrasound area $\left(\mathrm{mm}^{2}\right)$. Repeated-Measures Analysis of Variance for a comparison of the evaluation days of each group separately. To compare the groups on each day, an Analysis of Variance (ANOVA) was performed, and the significance level considered was $5 \%$ $(\mathrm{P}<0.05)$.

\begin{tabular}{llllll} 
Groups & \multicolumn{2}{l}{ Evaluation days } & \multirow{2}{*}{ P $^{*}$} \\
\cline { 2 - 5 } & 0 & 2 & 4 & 6 & \\
\hline Allogeneic & $48.0 \pm 13.0$ & $50.2 \pm 9.4$ & $53.2 \pm 10.4$ & $53.3 \pm 10.5$ & 0.183 \\
Autologous & $47.8 \pm 10.5$ & $48.6 \pm 4.6$ & $48.4 \pm 6.1$ & $50.9 \pm 5.3$ & 0.530 \\
Control & $46.5 \pm 5.2$ & $48.0 \pm 6.5$ & $47.3 \pm 4.9$ & $49.0 \pm 6.5$ & 0.481 \\
$P^{*}$ & 0.950 & 0.821 & 0.241 & 0.537 & \\
\hline
\end{tabular}

* The significance level considered was $5 \%(\mathrm{P}<0.05)$.

\section{Ultrasound}

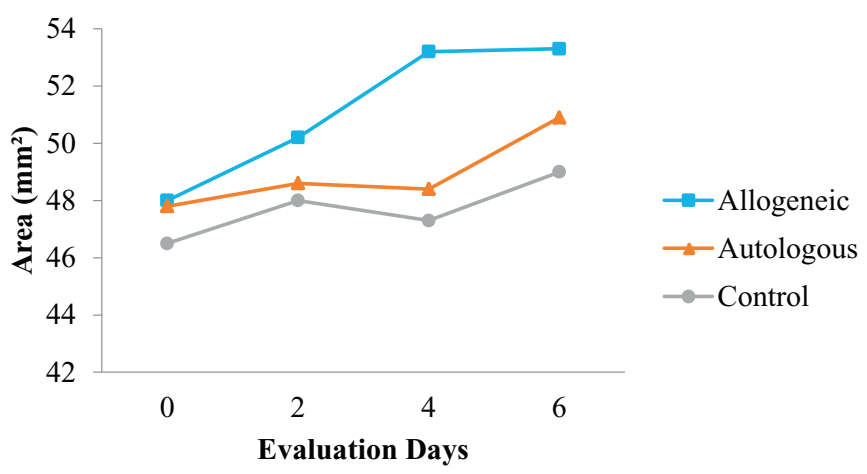

Fig. 2. Variation of the SDFT area $\left(\mathrm{mm}^{2}\right)$ evaluated by ultrasound in the different experimental groups, including the Gallog, Gauto and Gcont groups.

Table 1

Mean and standard deviation (SD) of the thermography $\left({ }^{\circ} \mathrm{C}\right)$ on different days among the groups using an Analysis of Variance (ANOVA).

\begin{tabular}{|c|c|c|c|c|c|}
\hline \multirow[t]{2}{*}{ Groups } & \multicolumn{4}{|l|}{ Evaluation days } & \multirow[t]{2}{*}{$\mathrm{P}^{*}$} \\
\hline & 0 & 2 & 4 & 6 & \\
\hline Allogeneic & $30.6 \pm 2.5 \mathrm{AB}$ & $32.4 \pm 1.2 \mathrm{~A}$ & $31.1 \pm 3.9 \mathrm{AB}$ & $28.6 \pm 2.0 \mathrm{~B}$ & 0.044 \\
\hline Autologous & $33.2 \pm 1.8 \mathrm{~A}$ & $32.5 \pm 0.7 \mathrm{~A}$ & $32.6 \pm 1.8 \mathrm{~A}$ & $29.2 \pm 2.6 \mathrm{~B}$ & 0.005 \\
\hline Control & $31.2 \pm 4.3$ & $32.9 \pm 1.6$ & $31.7 \pm 4.4$ & $30.5 \pm 1.1$ & 0.438 \\
\hline $\mathrm{P}^{*}$ & 0.157 & 0.784 & 0.519 & 0.328 & \\
\hline
\end{tabular}

${ }^{*} \mathrm{P}<0.05$ was considered significant for all the analyses. 
Table 3

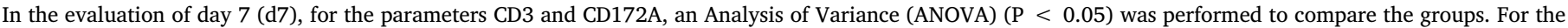
other parameters, a non-parametric Kruskal-Wallis Test $(\mathrm{P}<0.05)$ was conducted.

\begin{tabular}{|c|c|c|c|c|c|}
\hline Group & CD3 & CD172A & Factor VIII & Infiltrate & Type of inflammatory infiltrate \\
\hline Allogeneic & $3.13 \pm 0.80 \mathrm{ab}$ & $0.72 \pm 0.52$ & $1.0[0.72-1.95]$ & $2.0[2-3]$ & $1.0[1-1]$ \\
\hline Autologous & $4.97 \pm 2.30 \mathrm{a}$ & $0.61 \pm 0.51$ & $1.7[0.80-2.13]$ & $2.5[2-3]$ & $1.0[1-1]$ \\
\hline Control & $2.23 \pm 1.12 \mathrm{~b}$ & $0.23 \pm 0.10$ & $1.1[0.61-1.14]$ & $2.0[2-3]$ & $1.0[1-1]$ \\
\hline $\mathrm{P}$ & 0.024 & 0.141 & 0.414 & 0.686 & 1.000 \\
\hline
\end{tabular}

Means followed by the same lowercase letter in the column did not differ statistically from each other by a Tukey's test (P $>0.05$ ).

inflammatory infiltrate (score 3).

\subsection{Immunohistochemical analysis}

For qualifying tissue inflammation, the expressions of $\mathrm{CD} 3$ and CD172a and the microvascular density (Factor VIII) (Table 3) were evaluated in the tissue specimens. The presence of $\mathrm{T}$ lymphocytes was quantified by CD3 staining. The tissue samples from the Gauto group revealed a higher number of CD3-positive cells compared to the control group. There was no significant difference between the Gauto and Gallog or the Gallog and control groups. There was no significant difference in CD172 expression among the groups. Thus, the Gauto, Gallog and control groups revealed a similar CD172 expression. The microvascular density (MVD) was also evaluated by an assessment of antifactor VIII positive vessels. There was no significant difference in MVD among the groups. Therefore, all the groups had a similar number of positive blood vessels (Figs. 3 and 4).

\section{Discussion}

In the physical evaluation of the animals in this study, the perimeters of the thoracic limbs were modified as a whole as a function of time after the cell application. The allogeneic group presented a greater variation of perimetry, which was expected as the cells were from a different individual - although from the same species - and that could lead to a local reaction, different from what was observed by Carvalho et al. (2011). There was no significant difference among the groups regarding pain sensitivity to palpation, possibly because the inflammatory process was mild. All the groups presented mild pain sensitivity on the second day after the MSCs were applied, which disappeared on the following days, a fact that can be explained by the primary tissue response to an injury (application), including inflammation, activation, and local cell proliferation. Inflammation occurred after the application, which was also reported by Smith and Mcllwraith (2014), since the MSCs can increase the production of proinflammatory cytokines (Yan et al., 2014). In this study, the formation of a papule at the site of cell application was also observed, as reported by Pezzanite et al. (2015), which persisted at the injection site throughout the experiment. However, in the present study, the inflammatory process that occurred in the Gauto and Gallog groups was discrete and similar to each other.

Regarding the presence of heat, there was no significant difference between the groups, although Gallog presented a discrete heat oscillation at the application site when compared to the Gauto and Gcont groups. This result corroborates with what Carrade et al. (2011a) observed, a discrete dermal response to the injection of allogeneic cells in comparison with a saline solution, but this is a limited and self-resolution response.

The analysis of the lameness exam showed no significant difference between the groups, similar to the observations by Watts et al. (2011) and Carvalho et al. (2011). The animals presented degree 1 lameness after the application of the cells in $\mathrm{d} 2, \mathrm{~d} 4$ and $\mathrm{d} 6$, possibly due to the inflammatory response to an injury (Smith and Mcllwraith, 2014) caused by the application, causing the animals to feel a little bit of pain in the limb. However, although there was no significant difference, the
Gauto and Gallog groups had more animals with lameness than the Gcont group. This was expected because the presence of the cells in the tendon caused even a minimal local reaction.

The thermographic analysis revealed a temperature variation in the groups as a function of time. The temperatures of all the groups decreased on d6; although, the Gauto and Gallog groups had a greater variation in that moment, which was already expected by the presence of the applied cells and their effects of local immunomodulation (Yamada et al., 2013) and the paracrine effects, such as the production of anti-inflammatory and immunoregulatory molecules (Anderson and Bluestone, 2005; Seo et al., 2006, and Frassoni et al., 2008).

As for the ultrasonographic examination, no vascular flow was observed to the Power Doppler in the tendons prior to the cell application, which was in accordance with Carvalho et al. (2011). After the application, the Gauto, Gallog and Gcont groups presented blood flow (even though weak or moderate). However, there was no significant difference among the groups. The absent, weak, moderate, and intense scores changed little as a function of time in the neovascularization evaluation. However, the changes were without significant differences.

The tendon areas increased as a function of time for all the groups. The groups presented different behaviours from each other, and the greatest variation of the tendon area was observed in the Gallog group. This increase caused by the solutions injected into the tendon tissue was similar to that occurring in the tendon affected by natural injury, according to Dakin et al. (2013), as the application of both cells and PBS in a healthy tendon already consisted of something more in an intact area and, this way, led to the local increase.

The histopathological examination with the HE staining technique showed a discreet inflammatory reaction with subtle tissue disorganization at the AT-MSC transplantation site, and the presence of the inflammatory infiltrate, with lymphocyte predominance, was analysed in all the groups. This is a result that can be explained by Abbas et al. (2012) who reported that some of the progenitors of antigen-activated $\mathrm{B}$ and $\mathrm{T}$ lymphocytes undergo differentiation into memory cells that survive for long periods of time in a quiescent state. These memory cells are responsible for rapid and increased responses to subsequent exposures of the antigen. It should also be considered that only the physical action of administering $1 \mathrm{~mL}$ of solution in a dense tissue, such as the tendon, is enough to cause a tissue inflammatory response (Alves et al., 2011).

The difference related to the degree of tissue disorganization and the presence of lymphocytes and neovascularization between the Gauto and Gallog groups were not statistically significant when compared between them but was when compared to the Gcont group. The collagen fibres remained predominantly linear between the Gauto, Gallog and Gcont groups. However, the Gallog group showed a greater variation, as $50 \%$ of the samples were evaluated as linear and the others showed tissue disorganization $(<50 \%)$. This disorganization of the tendon tissue in the Gallog groups was justified by the more active presence of an inflammatory reaction at the allogeneic cell transplantation site, which was also found by Buja and Vela (2010). Although, in this study, the difference was not significant.

The fibroblasts were predominantly linear between the collagen fibres in all the groups, which was similar to that found by Carvalho et al. (2011), but in this study, the Gauto groups also showed the presence of 


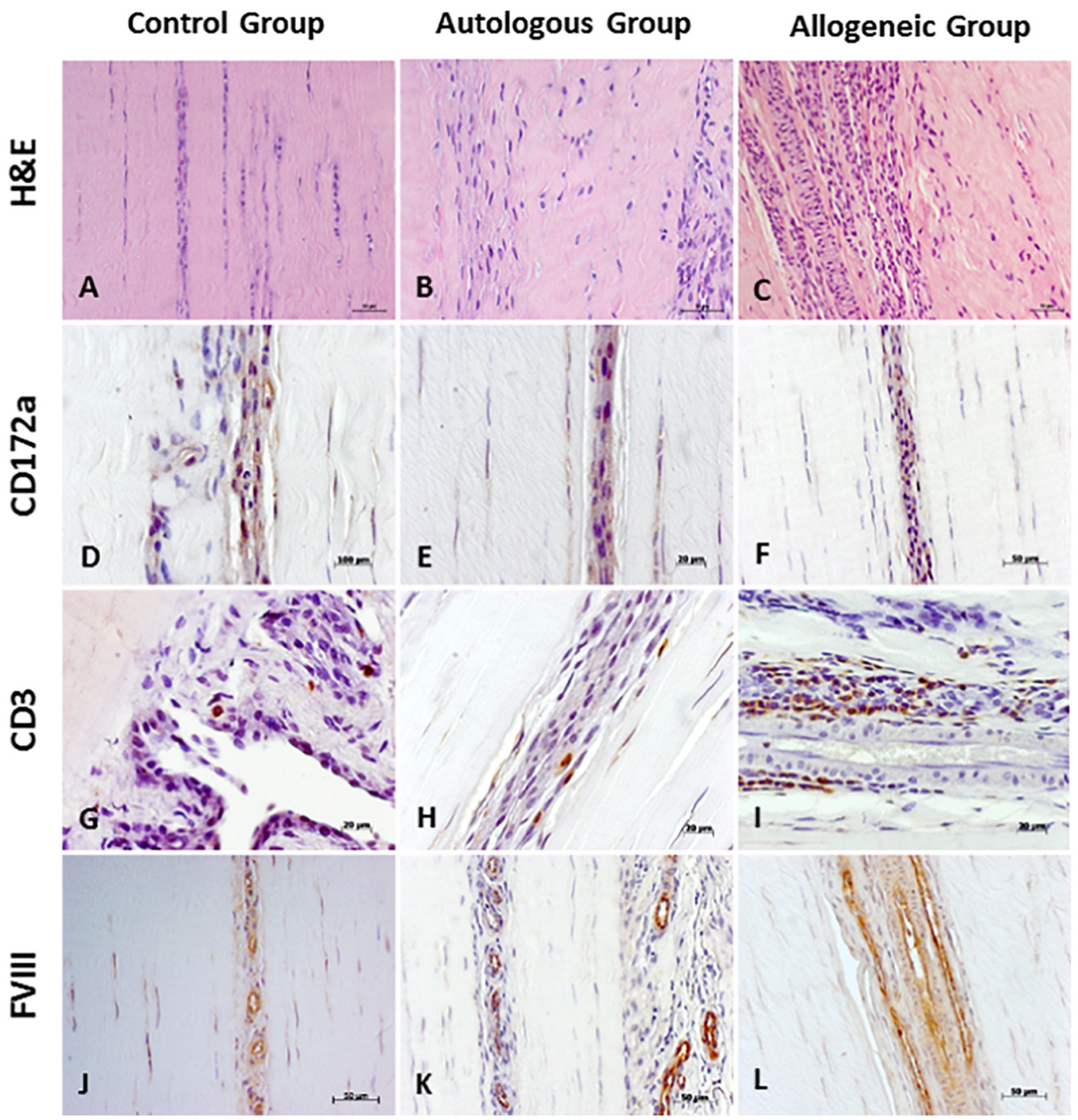

Fig. 3. Histopathology slides (haematoxylin-eosin (HE) staining) and immunohistochemistry of the SDFT of the autologous, allogeneic, and control groups. Immunostaining with the CD172a antibody for inflammatory infiltrate, CD3 for lymphocytes, and factor VIII for vessels in the Gcont, Gauto and Gallog groups, respectively.

moderately rounded fibroblasts, indicating that there was a change in the morphology of these cells. This fact is explained by the expansion capacity, differentiation, and chemotactic effect of the AT-MSCs (Yamada et al., 2013), which possibly activates the fibroblasts close to the application site.

In the neovascularization evaluation, the number of vessels marked by factor VIII presented no differences between the Gauto and Gallog groups, but there was a greater presence of vessels when compared to the Gcont group, which was expected because the MSCs stimulate the initial repair mechanisms, producing angiogenic growth factors (Anderson and Bluestone, 2005; Seo et al., 2006, and Frassoni et al., 2008); although, this was not statistically significant in this study. Carvalho et al. (2011) did not identify the presence of many vessels in most histological sections. Factor VIII was more marked in the Gauto and Gallog groups due to the presence of the cells. However, no statistically significant difference was observed between the groups of cells and in comparison to the control, which is possibly related to the absence of a pre-existing inflammatory stimulus, as the cells were applied in a healthy tendon. MSCs have a high immunomodulatory, regenerative and recovery capacity in addition to the trophic support they provide to damaged cells. They also regulate the paracrine secretion of growth factors, cytokines, antifibrotic factors and angiogenic mediators (Da Silva Meirelles et al., 2009).

Regarding the mononuclear inflammatory infiltrate, we qualified this by examining the expression of CD3, CD172 and MVD. We observed a high number of T-lymphocyte (CD3 positive) in the Gauto group compared to the Gallog and control groups. The high number of T-lymphocytes in the Gauto group was related to the antigen-activated $\mathrm{T}$ lymphocyte progenitors, which differentiated into memory cells that survive for long periods in a quiescent state. Although MSCs inhibit the proliferation of allogeneic $\mathrm{T}$ cells in the presence of inflammatory stimuli (Carrade Holt et al., 2014), even if the stimulus is minimal, it is assumed that the proliferation of $\mathrm{T}$ lymphocytes was inhibited in the Gallog groups and not in Gauto group. After applying the AT-MSCs in the SDFT, a higher presence of T lymphocytes was found in the Gallog and Gauto groups when compared to the Gcont group. The presence of stem cells may have recruited/activated lymphocytes to the application site, since MSCs modulate the response of cells of the innate and adaptive immune system ( $\mathrm{T}$ and B cells) (De Wolf et al., 2017).

The results of this study demonstrate that the AT-MSCs did not cause a significant response regarding the presence of $\mathrm{T}$ lymphocytes and inflammatory cells, as evaluated by the antibodies CD3 and 
A

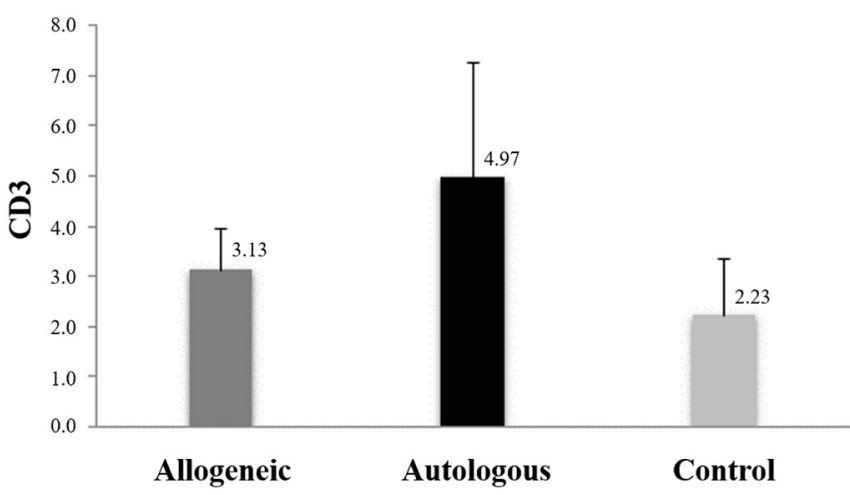

B

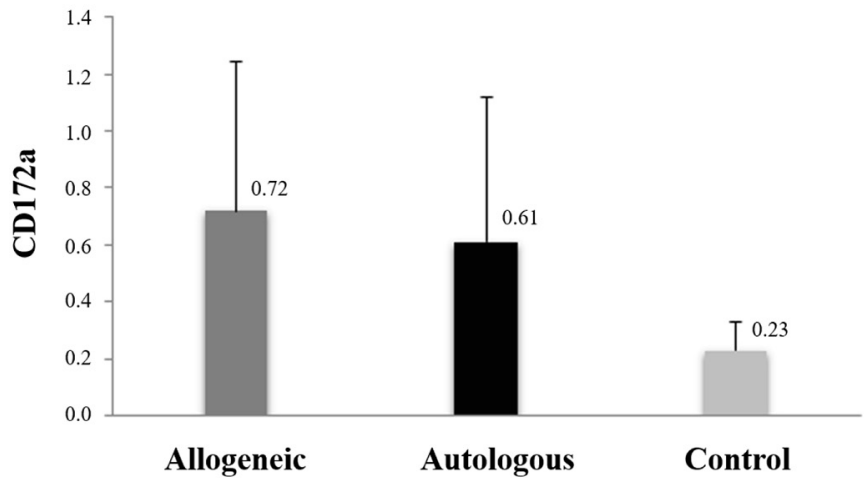

C

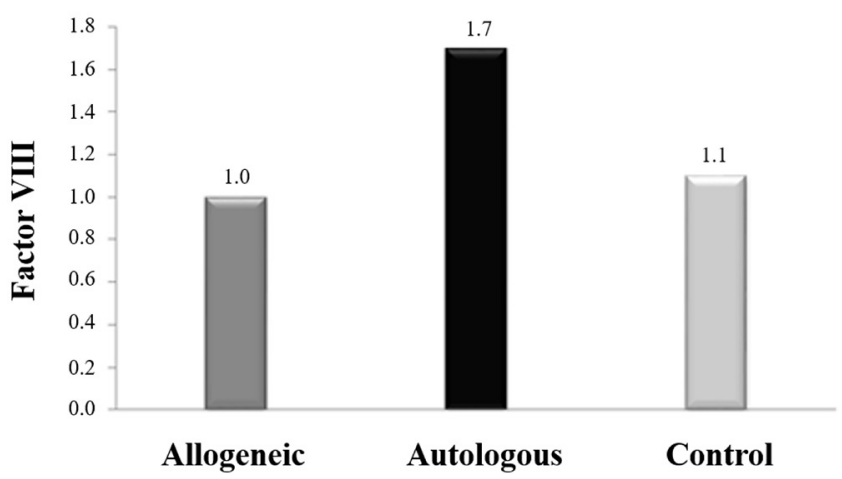

Fig. 4. A) Mean of the lymphocytes per $\mathrm{mm}^{2}$ in the $\mathrm{CD} 3$ sample. B) and C) Percentage of marked/positive area analysed by ImageJ for CD172a and factor VIII.

CD172a, respectively. Such results differed from what was observed by Pezzanite et al. (2015), which showed that BM-MSCs caused a strong antibody response after an intradermal injection in recipients with varied responses among them, and all the recipients developed antibodies against donor lymphocytes. Four of the recipient horses generated strong antibody responses from day 7 to day 14, and they persisted during the study. The variation in resistance of the recipient antibody responses was found in the study by Pezzanite et al. (2015) and was associated with the fact that the animals were recently added to the research herd of the group, which demonstrated that their immune systems were more sensitive than the other recipients due to inadequate nutrition before arrival at the university, auction stress, the associated transport, and from becoming new members of the herd. This situation did not occur in the present study, as the animals were already part of the same herd and were adapted to the place, conditions, nutrition and the other animals. The health condition and immune status of the animals are factors that influence the antibody response, as well noted by the present study and that by Pezzanite et al. (2015).

\section{Conclusion}

The allogeneic transplantation of AT-MSCs did not result in an adverse or inflammatory reaction that compromised the use of these cells in this experiment. Their behaviour was similar to that of autologous transplantation. Thus, the formation of allogeneic cell banks is favourable and safe. It is also important to emphasize the continuity of studies related to the immunomodulation of MSCs in order to clarify the activity of these cells and strengthen the clinical application based on increasingly safe results.

Supplementary data to this article can be found online at https:// doi.org/10.1016/j.rvsc.2018.03.012.

\section{Acknowledgements}

The authors extend their gratitude to the São Paulo Research Foundation (FAPESP) for awarding the Master's Grant number: 2013/ 17880-3 and to the National Council for Scientific and Technological Development (CNPq - number: 142322/2016-4 GD) for the research stipend of the doctoral grant that funded the publication of this article.

\section{References}

Abbas, A.K., Lichtman, A.H., Pillai, S., 2012. Imunologia Celular e Molecular, 7th ed. Elsevier, Rio de Janeiro.

Alberts, B., Johnson, A., Lewis, J., Raff, M., Roberts, K., Walter, P., 2004. Biologia Molecular da Célula, 4 ed. Artmed, Porto Alegre.

Alves, A.L.G., Stewart, A.A., Dudhia, J., Kasashima, Y., Goodship, A.E., Smith, R.K.W., 2011. Cell-based therapies for tendon and ligament injuries. Vet. Clin. North Am. Equine Pract. 27, 315-333.

Anderson, M.S., Bluestone, J.A., 2005. The NOD mouse: a model of immune dysregulation. Annu. Rev. Immunol. 23, 447-485.

Basile, R.C., Basile, M.T., Albernaz, R.M., Pereira, M.C., Araújo, R., Ferraz, G.C., Queiroz Neto, A., 2010. Guia prático de exames termográficos em equinos. Rev. Bras. Med. Equina 6, 24-28.

Borjesson, D.L., Peroni, J.F., 2011. The regenerative medicine laboratory: facilitating stem cell therapy for equine disease. Clin. Lab. Med. 31, 109-123.

Buja, M.L., Vela, D., 2010. Immunologic and inflammatory reactions to exogenous stem cells. Implications for experimental studies and clinical trials for myocardial repair. J. Am. Coll. Cardiol. 56, 1693-1700.

Caprnda, M., Kubatka, P., Gazdikova, K., Gasparova, I., Valentova, V., Stollarova, N., La Rocca, G., Kobyliak, N., Dragasek, J., Mozos, I., Prosecky, R., Siniscalco, D., Büsselberg, D., Rodrigo, L., Kruzliak, P., 2017. Immunomodulatory effects of stem cells: therapeutic option for neurodegenerative disorders. Biomed Pharmacother 91 60-69. http://dx.doi.org/10.1016/j.biopha.2017.04.034.

Carrade Holt, D.D., Wood, J.A., Granick, J.L., Walker, N.J., Clark, K.C., Borjesson, D.L., 2014. Equine mesenchymal stem cells inhibit t cell proliferation through different mechanisms depending on tissue source. Stem Cells Dev. 23, 1258-1265. http://dx. doi.org/10.1089/scd.2013.0537.

Carrade, D.D., Affolter, V.K., Outerbridge, C.A., Watson, J.L., Galuppo, L.D., Buerchler, S., Kumar, V., Walker, N.J., Borjesson, D.L., 2011a. Intradermal injections of equine allogeneic umbilical cord-derived mesenchymal stem cells are well tolerated and do not elicit immediate or delayed hypersensitivity reactions. Cytotherapy 13 , 1180-1192, 2011.

Carrade, D.D., Owens, S.D., Galuppo, L.D., Vidal, M.A., Ferraro, G.L., Librach, F., Buerchler, S., Friedman, M.S., Walker, N.J., Borjesson, D.L., 2011b. Clinicopathologic findings following intra-articular injection of autologous and allogeneic placentally derived equine mesenchymal stem cells in horses. Cytotherapy 13, 419-430.

Carvalho, A.M., Alves, A.L.G., Golim, M.A., Moroz, A., Hussni, C.A., Oliveira, P.G.G., Deffune, E., 2009. Isolation and immunophenotypic characterization of mesenchymal stem cells derived from equine species adipose tissue. Vet. Immunol. Immunopathol. 132, 303-306.

Carvalho, A., Alves, A., De Oliveira, P., Alvarez, L., Amorim, R., Hussni, C., Deffune, E., 2011. Use of adipose tissue-derived mesenchymal stem cell for experimental tendinitis therapy in equines. J. Equine Vet. Sci. 31, 26-34.

Carvalho, A.M., Badial, P., Álvarez, L.E.C., Yamada, A.L.M., Borges, A., Deffune, E., Hussni, C., Garcia Alves, A.L., 2013. Equine tendonitis therapy using mesenchymal stem cells and platelet concentrates: a randomized controlled trial. Stem Cell Res Ther 4, 85.

Da Silva Meirelles, L., Fontes, A.M., Covas, D.T., Caplan, A.I., 2009. Mechanisms involved in the therapeutic properties of mesenchymal stem cells. Cytokine Growth Factor Rev. 20, 419-427. http://dx.doi.org/10.1016/j.cytogfr.2009.10.002.

Da Silva, L., Fonseca-Alves, C.E., Thompson, J.J., Foster, R.A., Wood, G.A., Amorim, R.L., Coomber, B.L., 2017. Pilot assessment of vascular endothelial growth factor receptors and trafficking pathways in recurrent and metastatic canine subcutaneous mast cell 
tumours. Vet. Med. Sci. 3, 146-155. http://dx.doi.org/10.1002/vms3.66.

Dakin, S.G., Dudhia, J., Smith, R.K.W., 2013. Science in brief: resolving tendon inflammation. A new perspective. Equine Vet. J. 45, 398-400.

De Wolf, C., van de Bovenkamp, M., Hoefnagel, M., 2017. Regulatory perspective on in vitro potency assays for human mesenchymal stromal cells used in immunotherapy. Cytotherapy 19, 784-797. http://dx.doi.org/10.1016/j.jcyt.2017.03.076.

Dias, M.C., Landim-Alvarenga, F.D., de Moraes, C.N., da Costa, L.D., Geraldini, C.M., de Vasconcelos Machado, V.M., Maia, L., 2016. Intramuscular transplantation of allogeneic mesenchymal stromal cells derived from equine umbilical cord. Int. J. Stem Cells 9 (2), 239-249.

Díez-Tejedor, E., Gutiérrez-Fernández, M., Martínez-Sánchez, P., Rodríguez-Frutos, B., Ruiz-Ares, G., Lara, M.L., Gimeno, B.F., 2014. Reparative therapy for acute ischemic stroke with allogeneic mesenchymal stem cells from adipose tissue: a safety assessment: a phase II randomized, double-blind, placebo-controlled, single-center, pilot clinical trial. J. Stroke Cerebrovasc. Dis. 23, 2694-2700.

Frassoni, F., Gualandi, F., Podestà, M., Raiola, A.M., Ibatici, A., Piaggio, G., Sessarego, M., Sessarego, N., Gobbi, M., Sacchi, N., Labopin, M., Bacigalupo, A., 2008. Direct intrabone transplant of unrelated cord-blood cells in acute leukaemia: a phase I/II study. Lancet Oncol. 9, 831-839. http://dx.doi.org/10.1016/S1470-2045(08) 701803.

Gala, K., Burdzinska, A., Idziak, M., Wilczek, E., Paczek, L., 2013. Transplantation of mesenchymal stem cells into the skeletal muscle induces cytokine generation. Cytokine 64, 243-250.

Guadix, J.A., Zugaza, J.L., Gálvez-Martín, P., 2017. Characteristics, applications and prospects of mesenchymal stem cells in cell therapy. Med. Clín. 148, 408-414. English Ed.. https://doi.org/10.1016/j.medcle.2017.04.018.

Imhof, B.A., Aurrand-Lions, M., 2006. Angiogenesis and inflammation face off. Nat. Med. 12 (2), 171-172 Feb.

Mohammadi Ayenehdeh, J., Niknam, B., Rasouli, S., Hashemi, S.M., Rahavi, H., Rezaei, N., Soleimani, M., Liaeiha, A., Niknam, M.H., Tajik, N., 2017. Immunomodulatory and protective effects of adipose tissue-derived mesenchymal stem cells in an allograft islet composite transplantation for experimental autoimmune type 1 diabetes. Immunol. Lett. 188, 21-31. http://dx.doi.org/10.1016/j.imlet.2017.05.006.

Murata, D., Misumi, K., Fujiki, M., 2012. A preliminary study of diagnostic color Doppler ultrasonography in equine superficial digital flexor tendonitis. J. Vet. Med. Sci. 74, 1639-1642.

Nixon, A.J., Dahlgren, L.A., Haupt, J.L., Yeager, A.E., Ward, D.L., 2008. Effect of adiposederived nucleated cell fractions on tendo repair in horses with collagenase-induced tendinitis. Am. J. Vet. Res. 69, 928-937. http://dx.doi.org/10.2460/ajvr.69.7.928.

Pezzanite, L.M., Fortier, L.A., Antczak, D.F., Cassano, J.M., Brosnahan, M.M., Miller, D. Schnabel, L.V., 2015. Equine allogeneic bone marrow-derived mesenchymal stromal cells elicit antibody responses in vivo. Stem Cell Res Ther 6, 54. http://dx.doi.org/10. 1186/s13287-015-0053-x.

Seo, S., Fujita, H., Nakano, A., Kang, M., Duarte, A., Kume, T., 2006. The forkhead transcription factors, Foxc1 and Foxc2 are required for arterial specification and lymphatic sprouting during vascular development. Dev. Biol. 294, 458-470.

Smith, R., Mcllwraith, W., 2014. Advances in the understanding of tendinopathies: a report on the Second Havemeyer Workshop on equine tendon disease. Equine Vet. J. 46, 4-9.

Stashak, T.S., 2006. Claudicacão em Equinos Segundo Adams, 5 ed. Roca, São Paulo.

Tang, X., Qin, Y., Sheng, X., Xing, J., Zhan, W., 2017. Characterization of CD3+ T lymphocytes of Japonese flounder (Paralichthys olivaceus) and its response after immunization with formalin-inactivated Edwardsiella tarda. Fish Shellfish Immunol. 63, 220-227. http://dx.doi.org/10.1016/j.fsi.2017.02.024.

Tolar, J., Le Blanc, K., Keating, A., Blazar, B.R., 2010. Concise review: hitting the right spot with mesenchymal stromal cells. Stem Cells 28, 1446-1455. http://dx.doi.org/ 10.1002/stem.459.

Watts, A., Yeager, A., Kopyov, O., Nixon, A., 2011. Fetal derived embryonic-like stem cells improve healing in a large animal flexor tendonitis model. Stem Cell Res Ther 2,4 .

Whitcomb, M.B., 2004. Ultrasonographic evaluation of the metacarpus, metatarsus, and pastern. Clin. Tech. Equine Pract. 3, 238-255.

Yamada, A.L.M., Carvalho, A.M., Moroz, A., Deffune, E., Watanabe, M.J., Hussni, C.A., Rodrigues, C.A., Alves, A.L.G., 2013. Mesenchymal stem cell enhances chondral defects healing in horses. Stem Cell Discov. 3, 4.

Yan, Z., Zhuansun, Y., Chen, R., Li, J., Ran, P., 2014. Immunomodulation of mesenchymal stromal cells on regulatory $\mathrm{T}$ cells and its possible mechanism. Exp. Cell Res. 324 65-74. 